\title{
Effect of Drying on $\beta$-Carotene, $\alpha$-Carotene, Lutein and Zeaxanthin Content in Vegetables and Its Application for Vegetable Seasoning
}

\author{
Kullamethee Piyarach ${ }^{1,}$, Kamnerd Nipawan $^{2}$, Chumphukhaw Chadapon $^{1}$, Suwannasit Daluwan ${ }^{1}$, and Rotjanapun Kunjana ${ }^{1}$ \\ ${ }^{1}$ Department of Innovation and Product Development Technology, Faculty of Agro-industry, King Mongkut's University of \\ Technology North Bangkok, Prachinburi, Thailand \\ ${ }^{2}$ Yan Wal Yun Corporation Group Company Limited, Samut Sakhon, Thailand
}

\begin{abstract}
In plant based food with dark-green, yellow and orange color, beta $(\beta)$-carotene, alpha $(\alpha)$-carotene, lutein and zeaxanthin are predominating carotenoids contributing to an eyesight improvement. Among food preservation methods, drying using cabinet hot air dryer is one of the most cost-effective options and therefore, this investigation was aimed to study the carotenoids content in vegetables after drying and optimize the vegetable seasoning product. Based on customer survey, carrot, pumpkin, Chinese kale and long coriander were selected for the experiment, accessibility and have met the requirement of final moisture content, less than $10 \%$. Our results demonstrated that drying period of sliced carrots and pumpkins was 360 min, while in Chinese kale and long coriander was 240 min. Amounts of carotenoids in carrot and long coriander were greatly remaining after drying. Drying of Chinese kale had little effect on carotenoids content. While, dried pumpkin may cause a major loss of $\beta-, \alpha$-carotene and lutein content over $50 \%$. Regarding to development of vegetable seasoning powder, Just about right and Hedonic 9 point tests were used for a sensory evaluation. The optimal seasoning formula consisted of $66.8 \%$ mixed dried ground vegetables, $13.4 \%$ sugar, $8.8 \%$ salt, $6.7 \%$ garlic powder, and $4.3 \%$ white pepper powder. The overall acceptability of the product was rated as moderately liked, containing $\beta$-carotene, $\alpha$-carotene, lutein and zeaxanthin content as $178.04 \pm 3.39,58.81 \pm 1.83,158.89 \pm 4.16,0.98 \pm 0.01 \mu \mathrm{g} / \mathrm{g}$, respectively (vitamin A approximately $29.67 \mu \mathrm{g} \mathrm{RE} / \mathrm{g}$ ). Fortification of vegetable seasoning powder for daily consumption may improve the eye vision and reduce the rate of vitamin A deficiency.
\end{abstract}

\section{Introduction}

Vegetables are the sources of multi-vitamin and rich in dietary fibers. Vegetables are considered as the major part of dietary intakes regarding to their high level of nutrients and low in calories and this, in turn, essentially promotes health benefit and prevents an occurrence of chronic diseases [1]. Previously, numerous studies showed that vitamin A deficiency may lead to blindness, infections and premature birth and Provitamin A refers to the secondary plant substances [2]. Carotenoids are divided into sub-classes including $\alpha$-, $\beta$-carotene, $\beta$-cryptoxanthin. Lycopene predominantly appears in red, orange, and yellow fruit and vegetables, while lutein and zeaxanthin naturally occur in green leaved vegetables. Interestingly, leafy vegetables have greater contents of carotenoids than tuberous vegetables and beans including the stalks [3]. The importance of carotenoids in human nutrition is due to their health effects, varying from optical enhancement, antioxidant functions and is reported to fight noncommunicable diseases [4,5]. Other functions of these carotenoids, such as stimulating cell communication, enhancing immune system are also reported $[6,7]$. In addition, in leafy green vegetables (e.g., spinach, kale, and broccoli) maize, persimmons, etc., the groups of carotenoid-lutein and zeaxanthin, act as antioxidant to prevent photo-induced free radical damages [8]. Because eyes are more sensitive to oxidative stress compared with skins, lutein and zeaxanthin play a vital role to promote healthy vision including age-related macular degeneration and eye cataracts. Ratio of carotenoids distributes in the optical tissues in different patterns; in the retina, amount of lutein is greater than in zeaxanthin, while in the central macular, zeaxanthin is predominating. Combination of both types of carotenoid acts as preventers of the eye lens by protecting them from the damage by blue light entering the lens via the mechanism of an increase in macular pigmentation of ocular tissues [9].

At present, the variety of agro-products may need alternative options of preservation in order to reduce or stop spoilage, to maintain desired quality of nutritional properties for the longest shelf-life, and to create the value added products. Drying is one of the most common and cost-effective ways for preserving foods of all variety by application of low-temperatures in order to allow the highest retention of bioactive compounds comparable with the raw product $[10,11]$. The investigation of development of pumpkin powder product using tray drying method at $75^{\circ} \mathrm{C}$ was resulted in decreasing of color intensity as well as the $\beta$ - carotene content [12]. While, a

"Corresponding author: piyarach.k@agro.kmutnb.ac.th 
study of dehydration process of Moringa oleifera leaves using cabinet try dryer was observed as efficient as lyophilisation for retaining high content of total carotenoids $(60.1 \%)$, trans- $\beta$-carotene $(90.1 \%)$, cis-lutein (93.2\%) and $\alpha$-tocopherol (84.6\%) [13].

Carrot, pumpkin, Chinese kale and long coriander are considered as rich source of nutritionally important phytoconstituents. Plant usually contains similar type of carotenoids, however, content of carotenoid distributes differently in any parts of plants, depending on various factors such as stage of maturity, climate, cultivar, and farming practices [14]. Our selected vegetables are mostly produced by small farmer, and may be a source of carotenoids in the human diets, but they are highly perishable crop. To value-added, high carotenoids rich vegetable has been produced for using in seasoning products, where they may be used along main meals as an additive.

This research was therefore aimed to study the effect of drying method on carotenoids content in vegetables and to prepare a ready to use food product as vegetable seasoning powder for the greatest flavor for consumers as well as for foremost nutritional benefits. We highly expect that this seasoning product may be useful for the regular consumption in order to enhance vitamin A level.

\section{Materials and Methods}

\subsection{Materials}

Carrot (Daucus carota L.), pumpkin (Cucurbita moschata Duchesne), Chinese kale (Brassica oleracea L.) and long coriander (Eryngium foetidum L.) were selected from consumer survey (246 people) around Prachinburi, Thailand in order to prepare the vegetable seasoning product. All fresh vegetables were collected from Narasuan local market in Nernhom, Meung, Prachinburi, Thailand and prepared for drying in the same day.

Standards of carotenoids in this study included $\beta$-carotene (C9750, Sigma, USA), $\alpha$-carotene (0007, Carote Nature, Germany), Lutein (0133, Carote Nature, Germany), zeaxanthin (0119, Carote Nature, Germany)

\subsubsection{Preparation of the vegetables and drying process}

All Selected vegetables were cleaned. The tuberous vegetables were peeled off, carrot was sliced thinly circle shape about $3 \times 3 \times 0.2 \mathrm{~cm}$. and pumpkin was sliced about $3 \times 3 \times 0.5 \mathrm{~cm}$. While, leaf vegetables were cut in small pieces approximately $3 \mathrm{~cm}$. long. After that, the vegetables were soaked in $10 \%$ sodium chloride for $15 \mathrm{~min}$. In order to protect against damage mediated by Maillard reaction that changes the food color (Thailand Institute of Scientific and Technological Research, 2007). The vegetables were then air-dried before drying with hot air dryer. Each vegetable was dried using a tray dryer (trays x 10 perforated aluminum), which was produced by Kluay Nam Thai Trading Group Co, Ltd., Thailand. The temperature in the dryer was measured by thermocouple $\left( \pm 2^{\circ} \mathrm{C}\right)$. Sliced carrot, sliced pumpkin, Chinese kale leaf and long coriander leaf were placed uniformly as a thin layer on an aluminum plate. Drying experiments were performed at temperatures of $65^{\circ} \mathrm{C}$. During drying, the samples were weighed at $10 \mathrm{~min}$. intervals for $1 \mathrm{~h}$., after that were constantly determined every $30 \mathrm{~min}$. for $1 \mathrm{~h}$. and followed by every $60 \mathrm{~min}$. The loss of moisture content was determined by weighing the plate with a digital balance (Ohaus, Explorero EP 2140, Switzerland) to accuracy of $0.0001 \mathrm{~g}$. The required drying time to reach the final desired moisture content $(\leq 10 \%)$ was determined.

\subsubsection{Carotenoids ( $\beta$-, $\alpha$-carotene, lutein and zeaxanthin) evaluation}

Contents of $\beta-, \alpha$-carotene, lutein and zeaxanthin were evaluated by High-Performance Liquid Chromatography (HPLC) Alliance 2695, Waters HPLC and Waters 486 UV/VIS detector (Waters Corporation, USA). Samples were extracted in a dark room to protect carotenoids from degradation according the method of by Food and Nutrition Laboratory, Institute of Nutrition, Mahidol University, Nakhon Pathom, Thailand $[15,16]$. Briefly, samples were stored in plastic bags at $-20^{\circ} \mathrm{C}$ for a period not exceeding one month, weighted accurately 5-10 g and finely ground samples into a brown round-bottom flask. Samples were saponified by adding $10 \mathrm{~mL}$ of a freshly prepared aqueous solution of $10 \%$ ascorbic acid (Unilab, Australia) and $50 \mathrm{~mL}$ of $2 \mathrm{M}$ ethanolic potassium hydroxide (KOH) (Merck, Darmstadt, Germany). This solution was refluxed in a boiling water bath for $30 \mathrm{~min}$. Samples were then cooled to room temperature. After adding $70 \mathrm{~mL}$ of hexane (J.T. Baker, USA), the samples were mixed by continuous shaking for $2 \mathrm{~min}$. After separation of the two layers, the upper layer was transferred to a brown-glass separating funnel containing $50 \mathrm{~mL}$ of $5 \%$ (w/v) $\mathrm{KOH}$ solution. The samples were extracted twice with $35 \mathrm{~mL}$ of hexane. The combined hexane extract was washed with $100 \mathrm{~mL}$ of $10 \%$ (w/v) sodium chloride (UNIVAR, Ajax Finechem, Newzeland) and with a consecutive $100 \mathrm{~mL}$ water until it became alkali-free. An aliquot was collected and evaporated in a rotary evaporator (Buchi, Switzerland) under vacuum condition in a $37^{\circ} \mathrm{C}$ water bath. The residue of each sample was dissolved in $1 \mathrm{~mL}$ methylene chloride (J.T. Baker, USA) and $2 \mathrm{~mL}$ mobile phase. The solution was filtered through an ultrafilter $(0.20 \mu \mathrm{m})$ and injected into HPLC.

Separation of the carotenoids in each sample was performed using HPLC using C18 column (Vydac 201TP, C18 4.6 x $250 \mathrm{~mm}, 5 \mu \mathrm{m}$ column, Grace division, USA) with a guard column (Vydac 201TP, cartridge C18 $4.6 \mathrm{x}$ $12.5 \mathrm{~mm}, 5 \mu \mathrm{m}$, Grace division, USA) at a flow rate of 0.7 $\mathrm{mL} / \mathrm{min}$. at a controlled temperature at $30^{\circ} \mathrm{C}$ and monitored at $450 \mathrm{~nm}$. The mobile phase consisted of HPLC-grade acetonitrile (Lab Scan, Thailand): HPLC-grade methanol (Lab Scan, Thailand): methylene chloride (J.T. Baker, USA): triethylamine (Fluka, Switzerland): and ammonium acetate (Merck, Darmstadt, Germany) at a ratio of 90:8:2:0.085:0.085 (v/v/v/v and $\mathrm{w} / \mathrm{v})$. The results 
of carotenoid contents in both fresh and dried vegetables were analysed in duplicate and expressed as $\mu \mathrm{g} / \mathrm{g}$ dry weight

\subsubsection{Product development of vegetable seasoning}

Dried vegetables; carrot, pumpkin, Chinese kale, and long coriander were grinded using food processor at 180, 40, 90 and $120 \mathrm{sec}$, respectively. A basic formula of vegetable seasoning was prepared using dried ground carrot, dried ground pumpkin, dried ground Chinese kale leaves, dried ground long coriander leaves, sugar, salt, garlic powder, and white pepper powder at ratio 1:1:1:1:1:1:1:1. Sensory evaluations of this basic formula was performed by 50 untrained panellists using Just about right scale (much too little, too little, just right, too much, much too much) including 9-point Hedonic test $(1=$ dislike extremely, $5=$ neither like nor dislike, $9=$ like extremely). The vegetable seasoning $(1 \mathrm{~g})$ was served on top of $25 \mathrm{~g}$ of steamed rice for scoring of desirable attributes, such as color, odor, sweetness, saltiness, hotness, appearance and overall acceptability.

\subsubsection{Proximate composition analysis, physical and microbial properties}

The determination of proximate composition, such as moisture content, protein, fiber, ash and fat contents of the vegetable seasoning were performed following the official methods described by Association of Official Analytical Chemistry (AOAC 2005) on triplicate samples.

Water activity was evaluated using water activity meter (AQUA 3TE, USA). Colour properties were measured by Hunterlab MiniScan (ColorFlex, USA) and reported using the CIE system (International Commission on Illumination). $L^{*}, a^{*}$, and $b^{*}$ parameters indicated lightness, redness/greenness, and yellowness /blueness, respectively. Color measurement was carried out in three replicates for each treatment.

The product was monitored for microbial quality (total viable count of yeast and mold). The sample $(1 \mathrm{~g})$ was collected aseptically in a stomacher bag and 9 volumes of peptone solution $(0.01 \%, \mathrm{w} / \mathrm{v})$ were added. After homogenization in a Stomacher blender for $2 \mathrm{~min}$., a series of tenfold dilutions were made using the same solution.

\subsubsection{Statistical analyses}

The experiment was conducted in a completely randomized design with three replications. The results were subjected to analysis of variance and mean comparison by paired Student's t- test, in order to determine any significance of the differences in the data.

\section{Results and Discussion}

\section{1 Drying time of vegetables (carrot, pumpkin, Chinese kale and long coriander)}

Drying time curve of different vegetables was obtained and used to determine the drying characteristic. The drying process could be divided into three stages; the first stage represents a settling down period or initial adjustment period during which the solid surface conditions come into equilibrium with the drying air. The second stage is the constant rate period of drying and the surface of the solid remains saturated with liquid water. During drying, plant cells are destroyed; consequently, they become porous resulting in dehydration [17]. Falling rate period is the final stage, which is the rate of water movement from plant cells to the membrane surface for drying out $[18,19]$.

The optimal drying time of the selected vegetable was expected to reach the final moisture content less than $10 \%$ because this level of moisture may maintain the desirable quality of food products and their shelf-life. Information of drying time is important to decide whether the samples are suitable for time, energy saving and storage condition or for any other processing activities. Fig. 1 represented drying curves of sliced carrot and pumpkins with $360 \mathrm{~min}$. of drying period, while using $240 \mathrm{~min}$. of drying duration in Chinese kale and long coriander. Our observation explained that all vegetables at the first stage presented a gradually decrease of moisture content. Leafy vegetables lost moisture contents quicker than sliced tuburous vegetables. Drying curves are affected by many factors, which increase or decrease drying rates, for example, drying temperatures, shapes, dryer types, and food pieces thickness [20].
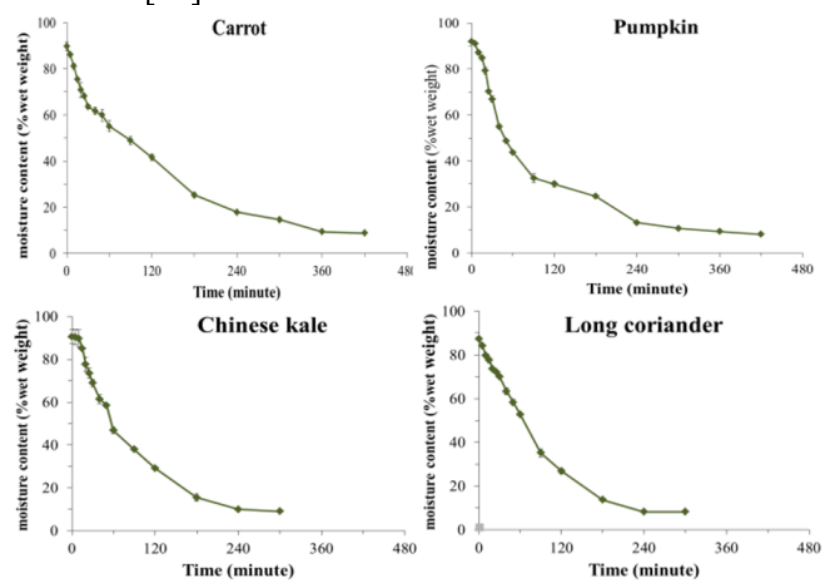

Fig. 1. Drying time and beta-carotene content of carrot, pumpkin, Chinese kale and long coriander

\subsection{Effect of drying on carotenoids content and changing of carotenoids content in vegetables}

In the present investigation, the main dietary sources of carotenoids are green leafy vegetable and colored fruits. The drying process of fresh vegetables had a drastic impact on bioactive compounds. The content of the studied carotenoids ( $\beta-, \alpha-$-carotene, lutein and zeaxanthin) in fresh and dried carrot, pumpkin, Chinese kale and long coriander are seen in Table 1. In this study, the main carotenoids detected in fresh carrot were $\beta$-carotene following by $\alpha$-carotene. While the highest content of lutein was observed in fresh pumpkin, Chinese kale and 
Table 1. Impact of drying process on the content of $\beta-, \alpha$-carotene, lutein and zeaxanthin in fresh and dried carrot, pumpkin, Chinese kale and long coriander

\begin{tabular}{|c|c|c|c|c|c|}
\hline \multicolumn{2}{|c|}{ Vegetables } & $\beta$-Carotene content $(\mu \mathrm{g} / \mathbf{g})$ & $\alpha$-Carotene content $(\boldsymbol{\mu g} / \mathbf{g})$ & Lutein content $(\boldsymbol{\mu g} / \mathbf{g})$ & Zeaxanthin content $(\boldsymbol{\mu g} / \mathbf{g})$ \\
\hline \multirow{2}{*}{ Carrot } & Fresh & $861.79 \pm 12.88$ & $382.38 \pm 5.49$ & $22.30 \pm 0.43$ & $2.70 \pm 0.04$ \\
\cline { 2 - 6 } & Dried & $773.66 \pm 8.56$ & $367.09 \pm 1.64$ & $22.07 \pm 0.43$ & $3.65 \pm 0.09$ \\
\hline \multirow{2}{*}{ Pumpkin } & Fresh & $66.30 \pm 1.51^{*}$ & $25.08 \pm 0.29^{*}$ & $383.98 \pm 10.96^{*}$ & ND \\
\cline { 2 - 6 } & Dried & $26.57 \pm 0.59$ & $8.42 \pm 0.15$ & $142.19 \pm 3.76$ & ND \\
\hline \multirow{2}{*}{ Chinese kale } & Fresh & $405.72 \pm 1.66^{*}$ & $\mathrm{ND}$ & $619.37 \pm 8.27^{*}$ & $49.95 \pm 0.79$ \\
\cline { 2 - 6 } & Dried & $304.27 \pm 6.98$ & $\mathrm{ND}$ & $441.44 \pm 1.44$ & ND \\
\hline \multirow{2}{*}{ Long coriander } & Fresh & $275.88 \pm 4.49$ & $1.77 \pm 0.11$ & $944.76 \pm 14.57^{*}$ & ND \\
\cline { 2 - 6 } & Dried & $269.07 \pm 1.27$ & $1.94 \pm 0.01$ & $659.47 \pm 12.76$ & ND \\
\hline
\end{tabular}

Data were presented as mean values. * Significant difference of each vegetable compared between fresh and dried sample using paired Student's t-test $(\mathrm{p}<0.05)$ for data analysis. $\mathrm{ND}=$ non detect

long coriander following with $\beta$-carotene. Zeaxanthin was not detected in pumpkin and long coriander. Many studies have reported that natural occurring carotenoids including lutein, zeaxanthin, $\beta$-, $\alpha$-carotene are abundantly detected in coloured fruits and vegetables. For instance, carrots (Daucus carota L.) contain $\beta$-, $\alpha$-carotene as the major pigments whilst lutein and $\beta$-carotene are greatly found in kale (Brassica oleracea var. sabellica) and pumpkin (Curcurbita moschata) is the rich source of $\beta-, \alpha-$ carotene, lutein, lycopene, $\beta$ - cryptoxanthin and zeaxanthin [14]. Moreover, the study of palm reported that the ratio of $\beta$-carotene in plant sources is often found in greater percentage than $\alpha$-carotene (e.g., crude palm oil; $\beta$-carotene: $60 \%$ while $\alpha$-carotene: $30 \%$ ) [21].

The effects of drying on the content of $\beta$-, $\alpha$-carotene, lutein and zeaxanthin were evaluated. All investigated carotenoids in carrot were reduced but not significantly different $(\mathrm{p} \geq 0.05)$. Likewise, there were no significant difference decreases $(p \geq 0.05)$ of $\beta$-, $\alpha$-carotene in long coriander. Whereas, the amount of carotenoids in pumpkin and Chinese kale were significantly decreased $(p<0.05)$, especially in dried pumpkin, we have found that over $50 \%$ of $\beta$-, $\alpha$-carotene and lutein content was diminished. Using tray drying method significantly reduces the amount and bioactivity of phytonutrients which may be causing by enzymatic processes that lead to significant changes in the composition of phytonutrients [22]. Mostly, carotenoid content in vegetable is decreased approximately $10-20 \%$ during drying process and further degraded when surface area is increase unless protection from air and light is introduced to stabilize the level of carotenoids [13, 23]. One such a benefit effect of using cabinet tray dryer, the retention of total carotenoids, tran- $\beta$-carotene, cis-lutein and DPPH activity was remained in the similar amount compared with those after lyophilisation suggesting that this method is as efficient as lyophilisation, yet cost saving [13].

\subsection{Optimal formula of vegetable seasoning product}

Sensory testing was a main focus for our product development. Therefore, Just about right scale was first used in order to measure an appropriateness of the level of the specific attributes (colour, odor, sweetness, saltiness, hotness, appearance and overall acceptability) in the vegetable seasoning's basic formula (4 dried ground vegetables were mixed with sugar, salt, garlic powder, and white pepper powder at the same ratio). The contents of ingredients were adjusted until all attributes of the basic formula were met "just right" level. The experiment revealed that an optimal formula of vegetable seasoning product consisted of $26.7 \%$ dried ground carrot, $26.7 \%$ dried ground pumpkin, $6.7 \%$ dried ground Chinese kale leaves, $6.7 \%$ dried ground long coriander leaves, $13.4 \%$ sugar, $8.8 \%$ salt, $6.7 \%$ garlic powder, and $4.3 \%$ white pepper powder (Table 2). Base on the result of sensory evaluation, the product had high quality score for desirable attributes such as colour, odor, sweetness, saltiness, hotness, appearance and overall acceptability was rated as moderately liked (score $=7.00 \pm 1.05$, $6.67 \pm 1.35,6.23 \pm 1.22,6.13 \pm 1.59,6.00 \pm 1.34,6.80 \pm 1.30$, and $6.90 \pm 1.18$, respectively) as shown in Fig. 2 .

Table 2. Ingredients of the vegetable seasoning powder

\begin{tabular}{|l|c|}
\hline \multicolumn{1}{|c|}{ Ingredients } & $\mathbf{\%}$ \\
\hline Dried ground carrot & 26.7 \\
\hline Dried ground pumpkin & 26.7 \\
\hline Dried ground Chinese kale leave & 6.7 \\
\hline Dried ground long coriander leave & 6.7 \\
\hline Fine sugar & 13.4 \\
\hline Salt & 8.8 \\
\hline Garlic powder & 6.7 \\
\hline White pepper powder & 4.3 \\
\hline
\end{tabular}

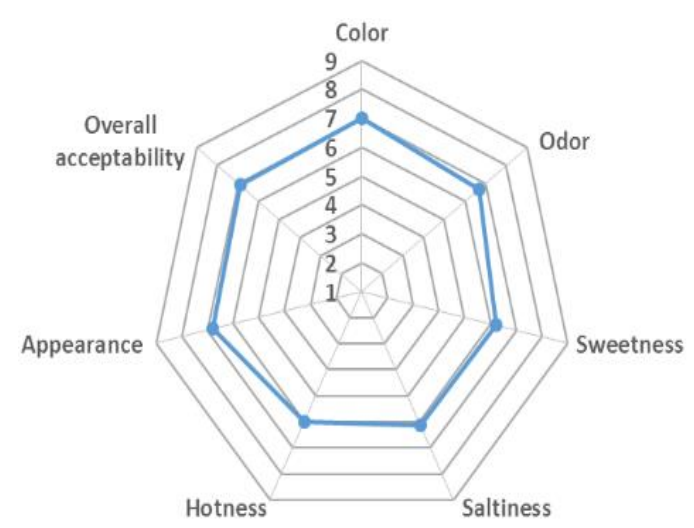

Fig. 2. Sensory profile of vegetable seasoning powder, showing the quality score of desirable attributes such as colour, odor, sweetness, saltiness, hotness, appearance and overall acceptability. 


\subsection{Proximate composition analysis, physical and microbial properties of vegetable seasoning}

Approximately, composition of vegetable seasoning product consisted of $61.23 \pm 0.13 \%$ fiber, $14.93 \pm 0.38 \%$ ash, $9.04 \pm 0.11 \%$ protein, $7.78 \pm 0.35 \%$ moisture content, $2.15 \pm 0.01 \%$ fat and $4.88 \%$ carbohydrate.

A gram of vegetable seasoning product contains $\beta$-carotene, $\alpha$-carotene, lutein and zeaxanthin content as $178.04 \pm 3.39,58.81 \pm 1.83,158.89 \pm 4.16,0.98 \pm 0.01 \mu \mathrm{g} / \mathrm{g}$, respectively. Theoretically, vitamin A (retinol) is converted mostly from $\beta$-carotene but lesser from $\alpha$-carotene and $\beta$-cryptoxanthin due to the greater conversion efficacy of $\beta$ - carotene. For example, two moles of retinol are generated by one mole of $\beta$-carotene, however the level of retinol produced from $\alpha$-carotene and $\beta$-cryptoxanthin is much lesser [24]. According to the information, these groups of carotenoids are able to be converted to vitamin A, approximately $29.67 \mu \mathrm{g} \mathrm{RE} / \mathrm{g}$. Supplementation of vitamin A for $80 \%$ of population in low income countries relies on consumption of provitamin A-carotenoids [25]. Additionally, the daily recommendation of a healthy adult is at least $200 \mu \mathrm{g} / \mathrm{d}$.

For evaluation of physical properties, the vegetable seasoning powder had water activity $0.41 \pm 0.01, L^{*}$ $56.25 \pm 0.01, a^{*} 0.85 \pm 0.04$ and $b^{*} 19.05 \pm 0.05$. The product was not exceed the level from the microbial standard of the seasoning powder of Thai product No.494/2547 (total microbial count $<1 \times 10^{6} \mathrm{CFU} / \mathrm{g}$, yeast and mold $<100 \mathrm{CFU} / \mathrm{g}$ )

\section{Conclusions}

Drying time of sliced carrot and pumpkin was recommended at 360 min., while Chinese kale and long coriander leaves was $240 \mathrm{~min}$. Amount of carotenoids in carrot and long coriander were greatly remained after drying. Content of carotenoids in Chinese kale has been very least affected by drying process. While, a major loss of $\beta-, \alpha$-carotene and lutein content was detected in dried pumpkin for over $50 \%$. The optimal seasoning formula consisted of mixed dried ground vegetables, sugar, salt, garlic powder, and white pepper powder. The overall acceptability of the product was rated as moderately liked containing $\beta$ carotene, $\alpha$-carotene, lutein and zeaxanthin content as $178.04 \pm 3.39,58.81 \pm 1.83,158.89 \pm 4.16,0.98 \pm 0.01 \mu \mathrm{g} / \mathrm{g}$, respectively and could be calculated $\beta$-carotene to vitamin A approximately $29.67 \mu \mathrm{g} \mathrm{RE} / \mathrm{g}$ ). The product was not exceeded the microbial standard. This formulation may be recommended for using in the regular consumption in order to fortify vitamin A level.

This research was funded by King Mongkut's University of Technology North Bangkok. Contract no. KMUTNB-GEN-59-60

\section{References}

1 K. M. Appleton, A. Hemingway, L. Saulais, C. Dinnella, E. Monteleone, L. Depezay, D. Morizet,
F.J. Armando Perez-Cueto, A. Bevan, H. Hartwell, Eur J Nutr. 55, 869-896 (2016)

2 S. Akhtar, A. Ahmed, M.A. Randhawa, S. Atukorala, N. Arlappa, T. Ismail, Z. Ali, J Health Popul Nutr. 31(4), 413-423 (2013)

3 A.J. Speek, S. Speek-Saichua, W.H.P. Schreurs, Food Chem. 27, 245-257 (1988)

4 A. Siepelmeyer, A. Micka, A. Simm, and J. Bernhardt, Chapter 8 - Nutritional Biomarkers of Aging. Molecular Basis of Nutrition and Aging. 109-120 (2016)

5 P. S. Bernstein, B. Li, P. P. Vachali, A. Gorusupudi, R. Shyam, B. S. Henriksen, J. M. Nolan, Prog Retin Eye Res. 50, 34-66 (2016)

6 J. Fiedor, K. Burda, Nutrients. 6(2), 466-488 (2014)

7 E.J. Johnson, Nutr Clin Care. 5(2), 56-65 (2002)

8 A. Alves-Rodrigues, A. Shao, Toxicol Lett. 150(1), 57-83 (2004)

9 C.S. Boon, D.J. McClements, J. Weiss, E. A. Decker. Crit Rev Food Sci. Nutr. 50(6), 515-532 (2010)

10 V. R. Sagar, P. Suresh Kumar, J Food Sci Technol. 47(1), 15-26 (2010)

11 K. Prabhat, N. Barjinder Pal Kaur,Arun S. Mujumdar, Drying Technologies for Foods: Fundamentals \& Applications, CHAPTER - 1 Fundamentals of Drying New India Publishing Agency, New Delhi, India. 122 (2015)

12 N. Aukkanit and S. Sirichokworrakit. Effect of dried pumpkin powder on physical, chemical, and sensory properties of noodle (Academics World 52 International Conference. Los Angeles, USA, 2016)

13 R. K. Saini, N. P. Shetty, Maya Prakash, P. Giridhar, J Food Sci Technol. 51(9), 2176-2182 (2014)

14 J. Nagarajan, R. Nagasundara, R. Mavinakere, E. Raghunandan, and et. al. In C. M. Galanakis (Eds). Nutraceutical and Functional Food Components: Effects of Innovative Processing Techniques. Chapter 8-Carotenoids. 259-296. (2017).

15 A. J. Speek, C. R. Temalilwa, J. Schrijver, Food Chem. 19, 65-74 (1986)

16 R. Kongkachuichai, R. Charoensiri, A. Kettawan, Pharm Sci Asia. 46(4), 218-230. (2019).

17 P.P. Lewicki, Trends in Food Sci \& Tech. 17(4), 153163 (2006)

18 R. Ihns, L. M Diamante, G.P. Savage, L. Vanhanen, J Food Sci. Technol. 46(2), 275-283 (2011)

19 S.V. Jangam, A.S. Mujumdar In S.V. Jangam, C.L. Law and A.S. Mujumdar (Eds). Basic concepts and definition drying of foods, vegetables and fruits. Singapore: 1, 1-30 (2010)

20 El-Shehawy, Sh. M., H. E. El-Mashad, J. Food and Dairy Sciences. 6(1), 355-366 (2010)

21 R Manorama, C. Rukmini. Nutrition Research. 12, 223-232 (1992)

22 I. Mueller-Harvey, Anim Feed Sci Tech. 91(1-2), 3$20(2001)$

"Corresponding author: piyarach.k@agro.kmutnb.ac.th 
23 F. M. Clydesdale, Chi- Tang Ho, C. Y. Lee, N. I Mondy, R.L. Shewfelt, CRC Crit Rev Anal Chem. 30(6), 599-638 (1991)
24 G. Tang, Int J Vitam, Nutr Res. 84, 25-29 (2014)

25 W. Stahl, H. Sies. Pigment \& Resin Technology. 44(1), 13-18 (2003) 